\title{
Emerging Equity Markets: To Invest Or Not To Invest?
}

Xavier Garza-Gómez, (Email: GarzaX@uhv.edu), University of Houston,Victoria Massoud Metghalchi, (Email: MetghalchiM@uhv.edu), University of Houston,Victoria

\begin{abstract}
Numerous studies suggest that investors diversifying their portfolios with equity of emerging markets benefit from increased returns and/or reduced volatility. Using a 16-year sample from 1988 to 2003, we test this assertion and find that ex-post benefits to U.S. investors in this period are small. Our tests show that the improvement in portfolio performance is not consistent through time, and it is statistically significant only when we restrict our analysis to some regions and/or specific time periods. We find that the lack of significant gains of diversifying into emerging markets is caused by problems with the two main sources of diversification benefits: contrary to expectations, emerging markets have low relative realized returns and their correlation with the U.S. stock market has increased over time.
\end{abstract}

\section{INTRODUCTION}

n spite of many studies supporting international portfolio diversification, a substantial "home country bias" still exists in portfolios of many U.S. investors. In this paper we look at the risk- return characteristics of emerging equity markets to investigate whether U.S. investors should consider investing part of their portfolio in them. Because Emerging Markets (EM) have traditionally had low correlations with the U.S. market, adding them in small doses could reduce portfolio risk and increase portfolio performance. According to Jorion and Miller (1997) the rationale for investing in EM is 1) emerging economies have higher expected economic growth than developed economies and, thus, offer potential for higher returns, and 2) emerging markets have low correlation of returns with the U.S. market and, therefore, offer diversification benefits when added to U.S. portfolios.

For decades, academics have documented the benefits of diversifying into EM (e.g., Levy and Sanat (1970), Errunza (1983), Errunza and Padmanabhan (1988), Bailey and Stulz (1990), De Santis (1993), Harvey (1993) Divecha et al. (1994), Harvey (1995), Erb, Harvey, and Viskanta (1997), Eaker, Grant and Woodard (2000)). This paper examines the empirical evidence underlying the view that adding emerging equity markets to a base portfolio was beneficial to U.S. investors during the 16-year time period ending in December, 2003. Our approach, however, differs from the literature in two aspects. First, many studies show only measures of relative performance. That is, most reports base their conclusions on point estimates, implicitly ignoring the statistical significance of the relation through time. To circumvent this limitation, we test the strength of our performance measure. Second, many studies concentrate on the general result and often overlook the causes for the improvement (or lack of) in performance. We address this issue by testing the significance of the two factors supposed to cause diversification benefits: higher returns of EM and low correlation relative to the domestic portfolio.

\section{DATA AND METHODOLOGY}

We use monthly data from Morgan Stanley Capital International (MSCI) ${ }^{1}$ over the period 1988-2003. The MSCI calculates an Emerging Market Free (EMF) Index as well as many regional indexes that are dollardenominated. The EMF is a capitalization-weighted index that is designed to measure equity market performance in the global emerging markets that would be attainable by U.S investors. That is, those indexes exclude equity not available to foreigners. For investors who are interested in particular world regions, MSCI also provides several 
capitalization-weighted regional sub-indexes. For our analysis we choose three main sub-indexes: the EMF Latin America Index, the EMF Asia Index and the EM EME (Europe Middle East) Index. ${ }^{2}$

Our methodology is straightforward. We assume a preferred domestic portfolio (S\&P 500) that a U.S. investor would like to diversify by adding emerging market equity to this base portfolio. We look at the Sharpe ratio of the base portfolio and compare it with the Sharpe ratios of the S\&P 500 index mixed with different proportions of EM. The Sharpe ratio (SR) is calculated $\left(\mathrm{R}_{\mathrm{i}}-\mathrm{R}_{\mathrm{f}}\right) / \square_{\mathrm{i}}$, where $\mathrm{R}_{\mathrm{i}}$ and $\square_{\mathrm{i}}$ are, respectively, the mean and standard deviation of returns for the asset $i$. In computing the Sharpe ratio, $\mathrm{R}_{\mathrm{f}}$, the risk free rate, is assumed to be zero. ${ }^{3}$ This comparison allows an initial assessment of the benefits of diversifying into emerging markets. Unfortunately, the Sharpe ratio, similar to other portfolio performance measures, produces relative, but not absolute, rankings of portfolio performance. That is, the fact that mixing the S\&P portfolio produces a higher SR for a sample doesn't say anything about the statistical significance of the difference. This criticism applies to all studies that concentrate on the improvements on the efficient frontier. As Bekaert and Urias (1999) stress, the benefits of diversifying into emerging markets may be sensitive to the period and/or the sample used for the test.

In an attempt to circumvent this problem, we test the statistical significance of the improvements in performance. We obtain a time series of relevant characteristics such as annual correlations and Sharpe ratios and use the 16 values for each portfolio to make inferences. This rough attempt to show persistence on diversification benefits complements previous studies like Barry, Peavy and Rodriguez (1998); Bekaert and Urias (1999) that analyze the diversification benefits by analyzing performance across subperiods. We use this approach to evaluate the performance of several diversified portfolios relative to that of the S\&P 500. Finally, in our attempt to better understand the origin of diversification benefits, we statistically test the basic assumptions of emerging markets: higher returns and low correlation.

\section{DESCRIPTIVE STATISTICS}

Table 1 shows descriptive data of the EM indexes used in our study. Consistent with the literature, we find that emerging markets have high volatility relative to the S\&P 500. Using monthly returns the standard deviation of EMF is $60 \%$ larger than S\&P. Volatility of regional indexes is much larger than the volatility of the EMF index. Nevertheless, despite the high volatility in all emerging markets, which should command a high return, the compounded return obtained by investing in EMF is lower than the U.S benchmark. Looking at the different regions, only Latin America provided a higher compounded return than the S\&P 500. In fact, even though EMF has a higher arithmetic average than the S\&P500, only Latin America has higher geometric and arithmetic averages than the S\&P500. ${ }^{4}$ Figure 1, which displays the year-by-year performance of the 5 indexes, shows that 1991 was extremely good for Latin America but bad for the EM-EME index. We can also see that the Asian crisis in 1997 caused the performance of EM-A to decline relative to the other indexes. When we consider the monthly correlation with the $\mathrm{S} \& \mathrm{P} 500$, we find that the broad index EMF has a value of 0.59, which is much higher than regional indexes and exceeds values previously reported in the literature. Monthly returns for all indexes, with the exception of EM-EME show negative skewness. Consistent with Bekaert, Erb, Harvey and Viskanta (1998), who report excess kurtosis for emerging markets; the kurtosis for EM indices in our sample is higher than the kurtosis for the S\&P500. Normality of monthly returns can be rejected for S\&P500 and all EM indices but EMF-A.

With annual returns, we see that the EMF Index was almost twice as volatile as the S\&P 500. The correlation of 0.36 between EMF and S\&P500 is much lower than for monthly returns. Skewness for yearly returns is positive for all emerging markets. The normality assumption can't be rejected for any of the indices. The differences in performance across regions suggest that investors may receive more benefits from regional allocation instead of using a "diversified" EM index like EMF.

\section{DIVERSIFICATION WITH A BROAD EM INDEX}

Our first set of tests involves the calculation of Sharpe ratios of portfolios that allocate a small fraction of investment to equity from emerging markets. Previous studies by Masters (1999) and Bekaert and Urias (1999) suggest that return enhancement and volatility reduction occur when between 5 and $10 \%$ of the equity portfolio is 
committed to emerging markets. Based on those studies we calculate results for portfolios with the proportion of emerging markets equity changing from 5\% to 30\% in increments of 5\%. The EMF index is our proxy for equity of emerging markets.

Table 1: Descriptive Statistics Of S\&P 500 And Emerging Markets Indexes, January 1988-December 2003

\begin{tabular}{rrrrrr}
\hline & S\&P 500 & EMF & EMF-A & EMF-LA & EM-EME \\
\hline Compounded return (whole period) & $350 \%$ & $343 \%$ & $106 \%$ & $1001 \%$ & $112 \%$ \\
Descriptive statistics using monthly returns (N=192) & & & \\
Arithmetic average & $0.88 \%$ & $1.02 \%$ & $0.65 \%$ & $1.72 \%$ & $0.75 \%$ \\
Geometric average & $0.79 \%$ & $0.78 \%$ & $0.38 \%$ & $1.26 \%$ & $0.39 \%$ \\
Standard deviation & $4.21 \%$ & $6.81 \%$ & $7.43 \%$ & $9.49 \%$ & $8.48 \%$ \\
Sharpe ratio & 0.208 & 0.149 & 0.088 & 0.182 & 0.088 \\
Correlation to S\&P 500 & n.a. & 0.589 & 0.530 & 0.481 & 0.369 \\
Maximum & $11.2 \%$ & $18.1 \%$ & $22.1 \%$ & $27.3 \%$ & $41.4 \%$ \\
Minimum & $-14.6 \%$ & $-29.3 \%$ & $-19.7 \%$ & $-35.4 \%$ & $-31.0 \%$ \\
Skewness & -0.45 & -0.63 & -0.11 & -0.59 & 0.38 \\
Kurtosis & 0.58 & 1.67 & 0.78 & 1.44 & 3.01 \\
Autocorrelation & -0.02 & $<0.0001$ & 0.11 & $<0.0001$ & $<0.0001$ \\
Descriptive statistics using annual returns (N=16) & 1 & 0.17 & 0.19 & 0.02 & 0.13 \\
Arithmetic average & $11.3 \%$ & $14.7 \%$ & $11.4 \%$ & $23.8 \%$ & $12.0 \%$ \\
Geometric average & $9.9 \%$ & $9.7 \%$ & $4.6 \%$ & $16.2 \%$ & $4.8 \%$ \\
Standard deviation & $17.9 \%$ & $35.3 \%$ & $40.4 \%$ & $47.1 \%$ & $43.2 \%$ \\
Sharpe ratio & 0.63 & 0.42 & 0.28 & 0.51 & 0.28 \\
Correlation to S\&P 500 & n.a. & 0.36 & 0.20 & 0.44 & 0.41 \\
Maximum & $34.1 \%$ & $71.3 \%$ & $96.4 \%$ & $144.4 \%$ & $86.0 \%$ \\
Minimum & $-23.4 \%$ & $-31.8 \%$ & $-49.0 \%$ & $-38.0 \%$ & $-34.5 \%$ \\
Skewness & -0.52 & 0.44 & 0.63 & 1.04 & 0.72 \\
Kurtosis & -0.99 & -1.46 & -0.11 & 1.34 & -1.10 \\
Autocorrelation & 0.51 & 0.42 & 0.61 & 0.27 & 0.41 \\
n-value for normality test & 0.13 & -0.29 & -0.18 & -0.28 & -0.50 \\
\hline
\end{tabular}

${ }^{1}$ Annual returns are compounded from January to December.

The first panel of Table 2 shows the Sharpe ratios obtained using monthly returns. We can see a trivial increase in the Sharpe ratios for 5\% and 10\% allocations of EMF and, as allocation increases beyond 10\%, a decline in the Sharpe ratio. We can report that the optimum allocation is $16.6 \%$ to EMF. ${ }^{5}$ Results obtained with annual returns, shown in the second panel, yield a similar conclusion: a small increase in the Sharpe ratios as we add EMF to the benchmark. The Sharpe ratio increases until 15\% of EMF is added and then slightly decreases. Optimum allocation is $12.2 \%$ to EMF. The third panel results are obtained from the 16 Sharpe ratios calculated over the period. Each Sharpe ratio was obtained with the 12 returns from January to December of each calendar year. Results for the improvement of Sharpe ratio are consistent with those shown in the two first panels. Moreover, the optimum allocation of EMF that maximizes the Sharpe ratio of the diversified portfolio is $10.5 \%$ of EMF, slightly lower than the value for the full time series of monthly returns. However, whether the observed difference is statistically significant or not is an important issue. To test it, we first used paired t-tests to assess the difference in average SR between the diversified portfolio and the benchmark portfolio (S\&P 500). Results based on the 16 years of data (not 
shown) indicate that there is no statistical difference between the two time series. Nevertheless, we report that this conclusion is dependent of the sample. In fact, one single observation, the $\mathrm{SR}_{\mathrm{SP} 500}$ for 1995 , exerts a strong influence on this analysis. Considering it in the study causes the hypothesis that the $\mathrm{SR}_{\mathrm{SP500}}$ is normal to be rejected. ${ }^{6}$ Trying to alleviate this problem, we include in Panel $\mathrm{C}$ results for a sign test that analyzes whether or not adding EM to the benchmark is beneficial to investors. The frequency of success events, where success is defined as a year in which $\mathrm{SR}_{\text {port }}>\mathrm{SR}_{\mathrm{SP} 500}$, and its corresponding p-value are shown in the last 2 rows. We can see that the improvement of using EMF is not statistically significant. Based on this result, we conclude that diversification benefits of EMF are insignificant for the whole period. ${ }^{7}$ The next sections will test whether this conclusion holds for the three regional portfolios and for different subperiods

Figure 1: Yearly Returns Of S\&P 500 And 4 Emerging Market Indexes, January 1988- December 2003

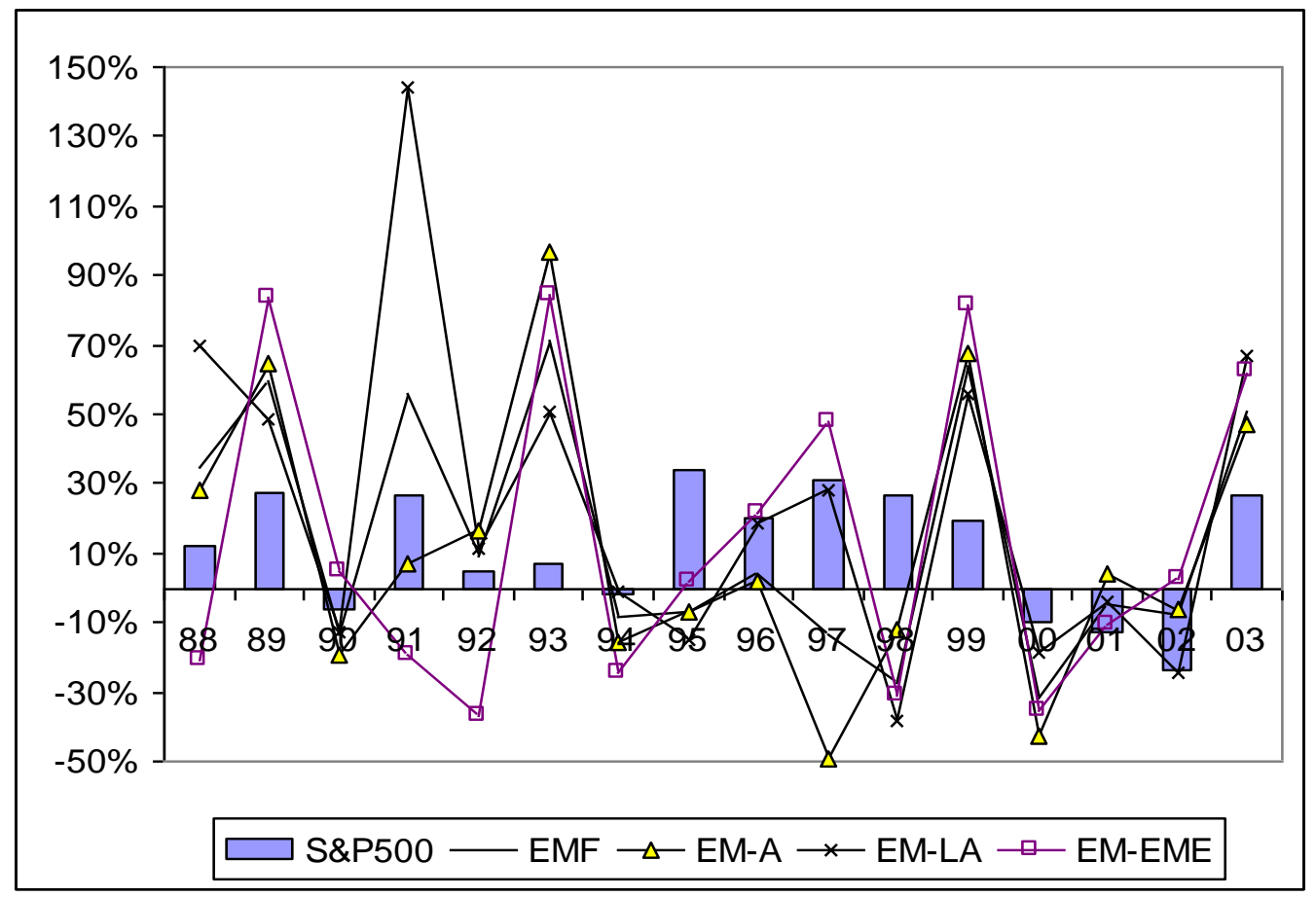

${ }^{1}$ Annual returns are compounded from January to December

\section{DIVERSIFICATION WITH REGIONAL EM INDEXES}

As Table 1 shows, performance among regions varies considerably. We now estimate the benefits of diversifying into one of the three regions defined above. In the previous section, we reported EMF optimal allocation ranged between 10.5 and 16.6 percent depending on the investment horizon. Based on the optimal levels we found, for the remainder of the paper we assume that investors will consider a $10 \%$ allocation in an EM index a good investment strategy with a reasonable exposure level. This value, which is also consistent with findings in Masters (1999) and Bekaert and Urias (1999), allows us to simplify our analysis. ${ }^{8}$ Accordingly, Table 3 shows the analysis of the Sharpe ratio obtained by portfolios that allocate $90 \%$ to the S\&P portfolio and $10 \%$ on regional emerging markets. 
Table 2: Sharpe Ratios Obtained Combining S\&P 500 With Different Proportions Of EMF Index, January 1988-December 2003

\begin{tabular}{|c|c|c|c|c|c|c|c|c|}
\hline & SP 500 & EMF & $\begin{array}{l}95 \% \mathrm{SP} \\
5 \% \mathrm{EMF}\end{array}$ & $\begin{array}{c}90 \% \mathrm{SP} \\
10 \% \mathrm{EMF}\end{array}$ & $\begin{array}{c}85 \% \mathrm{SP} \\
15 \% \mathrm{EMF}\end{array}$ & $\begin{array}{c}80 \% \text { SP } \\
20 \% \text { EMF }\end{array}$ & $\begin{array}{c}75 \% \mathrm{SP} \\
25 \% \mathrm{EMF}\end{array}$ & $\begin{array}{l}70 \% \mathrm{SP} \\
30 \% \mathrm{EMF}\end{array}$ \\
\hline \multicolumn{9}{|c|}{ A. Sharpe ratio $(\mathrm{SR})$ based on monthly returns $(\mathrm{N}=192)$} \\
\hline Average & $0.88 \%$ & $1.02 \%$ & $0.88 \%$ & $0.89 \%$ & $0.90 \%$ & $0.90 \%$ & $0.91 \%$ & $0.92 \%$ \\
\hline Std Deviation & $4.21 \%$ & $6.81 \%$ & $4.21 \%$ & $4.23 \%$ & $4.26 \%$ & $4.32 \%$ & $4.38 \%$ & $4.47 \%$ \\
\hline Sharpe ratio & 0.208 & 0.149 & 0.209 & 0.210 & 0.210 & 0.209 & 0.208 & 0.205 \\
\hline \multicolumn{9}{|c|}{ B. Sharpe ratio (SR) based on annual returns $(\mathrm{N}=16)$} \\
\hline Average & $11.3 \%$ & $14.7 \%$ & $11.5 \%$ & $11.6 \%$ & $11.8 \%$ & $12.0 \%$ & $12.1 \%$ & $12.3 \%$ \\
\hline Std Deviation & $17.9 \%$ & $35.3 \%$ & $17.7 \%$ & $17.7 \%$ & $17.8 \%$ & $18.1 \%$ & $18.5 \%$ & $19.1 \%$ \\
\hline Sharpe ratio & 0.631 & 0.416 & 0.648 & 0.658 & 0.663 & 0.662 & 0.656 & 0.645 \\
\hline \multicolumn{9}{|c|}{ C. Time-series of SR calculated every year ${ }^{1}(\mathrm{~N}=16)$} \\
\hline Average $S R$ & 0.325 & 0.203 & 0.330 & 0.332 & 0.331 & 0.327 & 0.320 & 0.313 \\
\hline \# years $S R_{\text {port }}$ & ats $S R_{S \& P}$ & 7 & 9 & 9 & 9 & 9 & 9 & 9 \\
\hline$p$-value of test for & frequencies & 0.77 & 0.40 & 0.40 & 0.40 & 0.40 & 0.40 & 0.40 \\
\hline
\end{tabular}

${ }^{1}$ Sharpe ratios are computed each year with monthly returns from January to December.

${ }^{2}$ Comparing performance of diversified portfolio against S\&P500

Table 3: Sharpe Ratios Of Portfolios Based On S\&P 500 And Several Emerging Markets Indexes

\begin{tabular}{|c|c|c|c|c|c|}
\hline & \multirow[b]{2}{*}{ S\&P 500} & \multicolumn{4}{|c|}{ Portfolios with $90 \%$ S\&P 500 and } \\
\hline & & $10 \% \mathrm{EMF}$ & $10 \%$ EMF-A & $10 \%$ EMF-LA & $10 \%$ EM-EME \\
\hline \multicolumn{6}{|c|}{ A. Sharpe ratio (SR) based on monthly returns $(\mathrm{N}=192)$} \\
\hline Average & $0.88 \%$ & $0.89 \%$ & $0.85 \%$ & $0.96 \%$ & $0.86 \%$ \\
\hline Std Deviation & $4.2 \%$ & $4.2 \%$ & $4.2 \%$ & $4.3 \%$ & $4.2 \%$ \\
\hline Sharpe ratio & 0.208 & 0.210 & 0.202 & 0.222 & 0.206 \\
\hline \multicolumn{6}{|c|}{ B. Sharpe ratio $(\mathrm{SR})$ based on annual returns $(\mathrm{N}=16)$} \\
\hline Average & $11.3 \%$ & $11.6 \%$ & $11.3 \%$ & $12.6 \%$ & $11.4 \%$ \\
\hline Std Deviation & $17.9 \%$ & $17.7 \%$ & $17.4 \%$ & $18.7 \%$ & $18.3 \%$ \\
\hline Sharpe ratio & 0.631 & 0.658 & 0.651 & 0.672 & 0.620 \\
\hline \multicolumn{6}{|c|}{ C. Times series of SR calculated every year ${ }^{1}(\mathrm{~N}=16)$} \\
\hline Average $S R$ & 0.325 & 0.332 & 0.321 & 0.336 & 0.323 \\
\hline \# year & port beats $S R_{S \& P}$ & 9 & 8 & 12 & 9 \\
\hline$p$-value for test of frequen & $S R_{\text {port }}>S R_{S \& P}$ & 0.40 & 0.60 & 0.04 & 0.40 \\
\hline
\end{tabular}

${ }^{1}$ Sharpe ratios are computed each year with monthly returns from January to December. 
Results based on monthly returns show that EMF-LA provided the highest SR. EMF provides a marginal increase while Asia and EME worsened the portfolio performance. Results based on annual returns also show that Latin America (EMF-LA) provides the greatest improvement to portfolio performance (highest SR). The broad EMF index is in second place with EMF-Asia in third. Investing in the EM Europe \& Middle East index, however, lowers the portfolio performance.

Using the time series of SR, results are consistent with those in Panel A; EMF-LA yields the highest average SR, EMF is in second place and the other two indices worsen the performance of the benchmark. Statistical tests based on the time series (not shown) fail to find differences between the diversified portfolios and the benchmark. Even EMF-LA, which produced the highest Sharpe ratio, doesn't appear significant. ${ }^{9}$ However, based on the sign test, we can see that investing 10\% in EMF-LA was better than investing only in the S\&P 500 in 12 out of 16 years. This frequency of successes is statistically significant, which suggests that using the Latin America portfolio to diversify the S\&P500 consistently improves portfolio performance.

An interesting evaluation exercise is to determine how far a $10 \%$ allocation in the EM indexes is from the optimum level for each region. For comparison purposes, we report that the optimum allocation levels that maximize average SR for the 16 years of our sample are $2.7 \%$ for Asia, $8.2 \%$ for Latin America and $4.4 \%$ for Europe \& Middle East. Optimal levels for Asia and Europe \& Middle East turned out lower than EMF Latin America. We stress, however, that these values are sample dependent, and since they were obtained ex post, we can't expect to hold for future periods.

Faced with the marginal benefits of diversifying into emerging markets, we now analyze the causes for these results. To do so, we test the three characteristics that are supposed to be the origin of diversification benefits: high volatility, higher returns commensurate with the higher risk level, and low correlation to the benchmark portfolio. A summary of statistical tests is shown in Table 4 . The first panel shows tests done with monthly returns. When we first test the difference of risk between S\&P and EM indexes, we see a significantly higher risk for emerging markets. Since monthly returns for most of our indices are nonnormal, we compare the indices using a sign test; ${ }^{10}$ we measure the number of months in which the return on an EM Index is higher than the return on S\&P 500. Results show that only EMF surpasses S\&P 500 more frequently than a completely random process would dictate. This is good news for investors expecting diversification benefits from EMF. The caveat, however, is that a few months with extreme negative returns can more than eliminate the effects of many months with positive returns. Skewness and kurtosis estimates shown in Table 1 suggest that this is the case. The other indices (even EMF-LA) fail to consistently beat the benchmark.

When we test risk, the results based on annual returns (Panel B) are similar to those with monthly returns, i.e. risk is significantly higher for EM indexes than for the S\&P 500. Nevertheless, both the parametric and the nonparametric tests suggest that average annual returns of EM indexes are statistically indistinguishable from the average return of the S\&P 500. The index closest to achieving significance on the t-test was EMF-LA, with a p-value of 0.13 .

So far we've seen evidence that investing in EM indices is riskier than investing in the S\&P500 but most EM don't provide consistently higher returns to compensate for the higher risk. We now explore the third possible source of benefit to diversification: the correlation between the benchmark and the proposed indices.

Even if their expected return is practically the same, combining a benchmark portfolio with a riskier asset can provide diversification benefits as long as the correlation between portfolios is below a certain critical level. This level can be derived from the following equation:

$$
\sigma_{p}=\left(X_{S P}^{2} \sigma_{S P}^{2}+X_{E M} \sigma_{S P}^{2}+2 X_{S P} X_{E M} r_{S P-E M} \sigma_{S P} \sigma_{E M}\right)^{\frac{1}{2}}
$$

which corresponds to the standard deviation of a two-asset portfolio consisting of S\&P 500 (SP) and an emerging market index (EM). Assuming that $90 \%$ is invested in SP and $10 \%$ in EM, we can easily calculate a critical correlation level under which diversification benefits would be significant. The critical correlation values shown in 
Table 4 correspond to levels of relative risk of $2 \square_{\text {SP }}$ for EMF, $2.25 \square_{\text {SP }}$ for EMF-A, $2.6 \square_{\text {SP }}$ for EMF-LA, and $2.4 \square_{\text {SP }}$ for EM-EME, where $\square_{\text {SP }}$ corresponds to the standard deviation of the benchmark portfolio (S\&P 500). Testing if average correlation falls below the critical level shows that the correlation of all the EM indices with S\&P is just too high to provide diversification benefits.

Table 4: Average Return, Risk And Correlation For Emerging Markets Indexes

\begin{tabular}{|c|c|c|c|c|}
\hline & EMF & EMF-A & EMF-LA & EM-EME \\
\hline \multicolumn{5}{|l|}{ A. Tests using monthly returns $(\mathrm{N}=192)$} \\
\hline p-value for test that var $E M>\operatorname{var} S \& P$ & 0.0000 & 0.0000 & 0.0000 & 0.0000 \\
\hline \# months EM beats $S \& P$ & 109 & 99 & 105 & 92 \\
\hline$p$-value for test of frequency of $E M>S \& P$ & 0.04 & 0.36 & 0.11 & 0.74 \\
\hline \multicolumn{5}{|l|}{ B. Tests using annual returns $(\mathrm{N}=16)$} \\
\hline p-value for test that var $E M>\operatorname{var} S \& P$ & 0.013 & 0.003 & 0.001 & 0.001 \\
\hline$p$-value for test that avg $E M>\operatorname{avg} S \& P$ & 0.35 & 0.50 & 0.13 & 0.47 \\
\hline \# years EM beats $S \& P$ & 9 & 8 & 9 & 7 \\
\hline \multicolumn{5}{|l|}{ C. Test of correlation using time-series $(\mathrm{N}=16)$} \\
\hline Critical correlation to $S \& P 500^{1}$ & 0.42 & 0.34 & 0.26 & 0.31 \\
\hline Avg one-year correlation to $S \& P 500$ & 0.55 & 0.50 & 0.47 & 0.29 \\
\hline p-value for test that avg correl $<$ Critical value & 0.95 & 0.98 & 0.99 & 0.44 \\
\hline
\end{tabular}

\section{SUBPERIOD ANALYSIS}

Since the overall volatility of our sample period is considerable, we certainly expect some difficulty attaining statistical significance in our tests. However, if diversification benefits persist for a number of consecutive years, we may find significance for some combination of region and subperiod. Table 5 shows the Sharpe ratios obtained using four 4-year subperiods and two 8-year subperiods. When we look at the average Sharpe ratio in Panel A, we can see that including Latin America in the first subperiod yielded the highest increase in average SR. For the second subperiod, including Asia was the best option, while for the last two 4-year subperiods, adding EME yielded the highest average SR. When we use 8-year subperiods, Latin America and EME are the winners for the first and second subperiods. However, the improvements in average SR are relatively small, so statistical significance must be assessed. To do that, first we use a nonparametric test (the sign test) to compare whether the SR of the portfolio is higher than the SR of the S\&P 500. Results indicate that only EMF-LA can achieve statistical significance in one 4year subperiod and one 8-year subperiod. Panel B, which shows the t-test results of comparing the time series of SR confirms the improvement for EMF-LA only in the first 4-year subperiod. Panel B also suggests significance for the broad index EMF during the first subperiod. Overall evidence in Table 5 suggests that the benefits of diversification are not consistent through time or region but tend to concentrate for combinations of region and subperiod.

Table 6 shows the behavior of the three factors affecting portfolio performance in the subperiods. The first panel shows that the volatility of emerging markets is always higher than the volatility of the benchmark across all subperiods. This excess volatility is particularly significant for the period 1996-1999, where the S\&P 500 had a period of low volatility and for the longer period 1988-1995.

The second panel shows that only the first subperiod provided a situation where diversification significantly paid off. Nevertheless, not all the regions turned out ahead. Only Latin America and the broad index yielded 
significant benefits. Results for the 8-year subperiods are similar. However, as already stressed above, 1991 was an extremely good year for Latin- American markets. This spike is causing the significant results for the subperiod. We can report these results are robust to the use of monthly returns instead of annual returns. Consistent with evidence in Table 4, when the sign test is applied to yearly returns, none of the indices is better than S\&P 500. However, evidence for monthly returns, confirms that EMF and EMF-LA had higher returns in the first subperiod.

Table 5: Sharpe Ratios Of Portfolios Based On S\&P 500 And Several Emerging Markets Indexes Subperiod Analysis

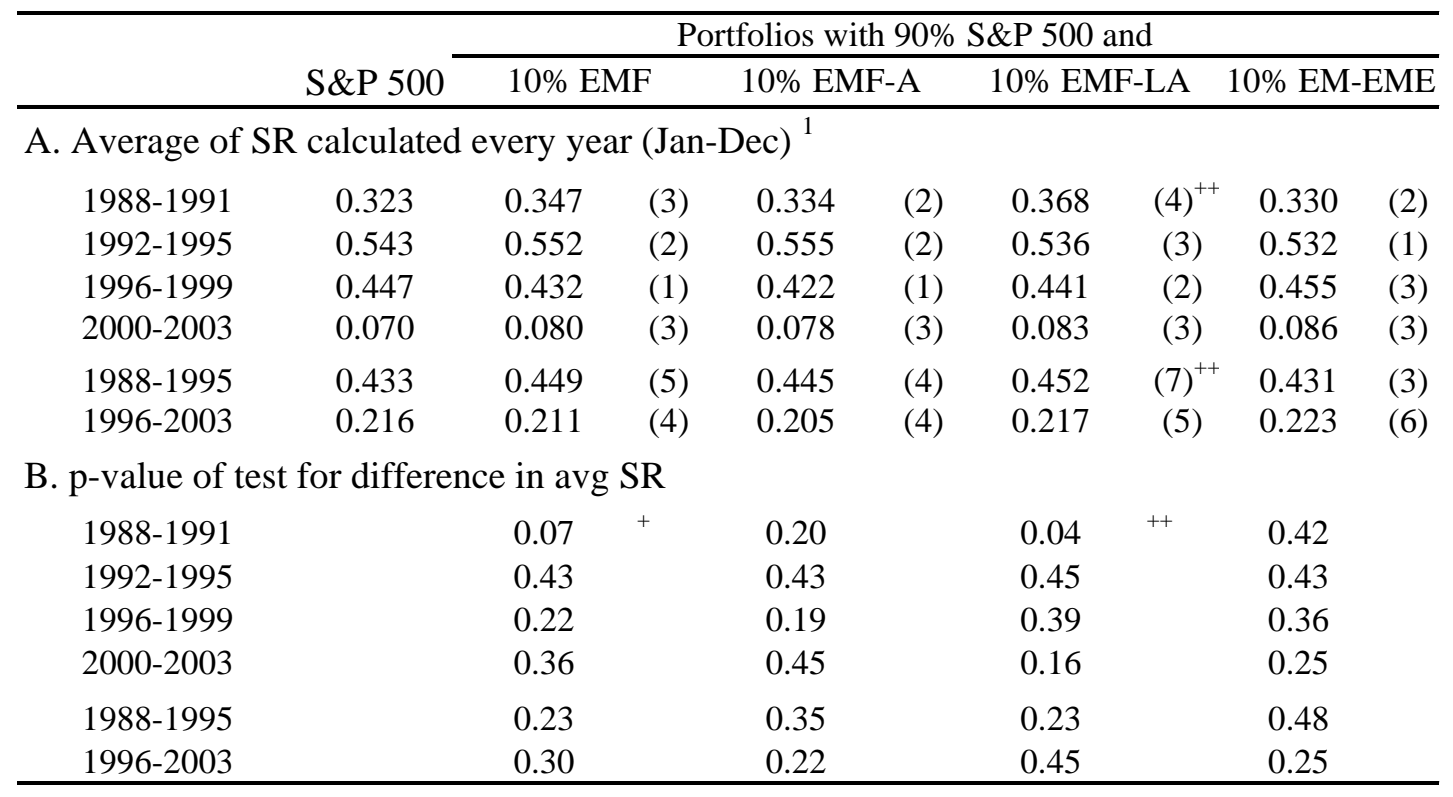

${ }^{1}$ Number in parentheses identifies the frequency in which the SR for the SP-EM portfolio is higher than the SR for the SP500. ${ }^{+}$Statistically significant at the $10 \%$ level. ${ }^{++}$Statistically significant at the $5 \%$ level.

The last panel of Table 6 shows average correlations with S\&P 500 of the EM-indexes. Three interesting results emerge from this table. First, the Europe \& Middle East index had a negative correlation with S\&P in the first 4-year subperiod, and for the first 8-years of the sample, it was significantly below the critical level to reduce risk. Unfortunately, portfolio performance wasn't improved because of the lower return during the period. EMF-A also had a low correlation with S\&P in the second subperiod, which caused the higher average SR reported in Table 5, but not low enough to make it significant. For the 8-year subperiods we find that the broad index EMF and the EME index had correlation to S\&P500 significantly lower than the critical values. Finally, Panel C shows a clear tendency of correlation to increase in time. For the broad index (EMF), correlation coefficients go from 0.36 in the first 8 -year subperiod to 0.74 in the second subperiod. This trend is better observed in Figure 2, where we see how EM-EME's correlation to S\&P 500 goes from negative values in 1988-90 to values around 0.7 in 2001-2003. This overall trend across indexes suggests an increasing integration of the emerging markets with the U.S. economy. This integration may have different effects on investors. If integration causes internal volatility to decrease, then investors will benefit from the reduced risk. However, if correlation increases without a decrease in volatility, the effect on investors is negative. As observed in Figure 2, during four international crises in our sample period: the Gulf War (1991), the Mexican crisis (1994), the Asian crisis of 1997 and the terrorists attacks to the US (2001), correlation between EM and S\&P has spiked. If this recent phenomenon persists in time, the small benefits of diversification will further decrease. 
Table 6: Average Return, Risk And Correlation For Emerging Markets Indexes. Subperiod Analysis

\begin{tabular}{|c|c|c|c|c|c|}
\hline & S\&P500 & EMF & EMF-A & EMF-LA & EM-EME \\
\hline \multicolumn{6}{|c|}{ A. Standard Deviation ${ }^{1}$} \\
\hline 1988-1991 & $16 \%$ & $34 \%$ & $36 \%$ & $65 \%^{++}$ & $52 \%^{+}$ \\
\hline 1992-1995 & $16 \%$ & $38 \%$ & $51 \%^{+}$ & $28 \%$ & $52 \%^{+}$ \\
\hline 1996-1999 & $5 \%$ & $40 \%^{++}$ & $49 \%^{++}$ & $39 \%^{++}$ & $44 \%+$ \\
\hline $2000-2003$ & $22 \%$ & $35 \%$ & $37 \%$ & $42 \%$ & $40 \%$ \\
\hline $1988-1995$ & $15 \%$ & $34 \%+$ & $41 \%^{++}$ & $54 \%^{++}$ & $48 \%{ }^{++}$ \\
\hline 1996-2003 & $21 \%$ & $35 \%$ & $40 \%$ & $38 \%$ & $41 \%$ \\
\hline \multicolumn{6}{|c|}{ B. Compounded returns ${ }^{1}$} \\
\hline 1988-1991 & $69 \%$ & $189 \%^{+}$ & $82 \%$ & $440 \%^{+}$ & $11 \%$ \\
\hline $1992-1995$ & $48 \%$ & $59 \%$ & $80 \%$ & $41 \%$ & $0 \%$ \\
\hline 1996-1999 & $139 \%$ & $7 \%$ & $-24 \%{ }^{--}$ & $47 \%$ & $104 \%$ \\
\hline $2000-2003$ & $-24 \%$ & $-10 \%$ & $-17 \%$ & $-2 \%$ & $-7 \%$ \\
\hline 1988-1995 & $149 \%$ & $358 \%^{+}$ & $228 \%$ & $663 \%^{+}$ & $12 \%$ \\
\hline $1996-2003$ & $81 \%$ & $-3 \%$ & $-37 \%$ & $44 \%$ & $90 \%$ \\
\hline \multicolumn{6}{|c|}{ C. Average one-year correlation to S\&P500 } \\
\hline 1988-1991 & & 0.40 & 0.57 & 0.24 & $-0.05^{-}$ \\
\hline $1992-1995$ & & 0.31 & $0.15^{-}$ & 0.30 & $0.06^{--}$ \\
\hline 1996-1999 & & 0.70 & 0.65 & 0.59 & 0.49 \\
\hline $2000-2003$ & & 0.78 & 0.64 & 0.76 & 0.68 \\
\hline 1988-1995 & & $0.36^{-}$ & 0.36 & 0.27 & $0.00^{--}$ \\
\hline $1996-2003$ & & 0.74 & 0.64 & 0.68 & 0.58 \\
\hline
\end{tabular}

${ }^{1}$ Tests on standard deviation and mean returns are done with annual returns. (EM > SP) Tests on correlation are done with 4 observations of one-year correlations compared to the critical values.

+ Statistically significant at $10 \%$ level. ${ }^{++}$Statistically significant at the $5 \%$ level.

\section{IMPLICATIONS FOR PORTFOLIO MANAGERS}

Since diversification into emerging markets only pays off when the selected country or region significantly outperforms the rest, investors will naturally want to be in that particular market at the time when the next spike occurs. Unfortunately, since cases of extreme positive performance are rare and difficult to predict, U.S. investors will have to choose a position in the passive-active spectrum of investment management to try to maximize their performance. On one side, they can invest all of their resources destined for EM into a broad index (such as EMF) and hope that the next spike will help them improve performance. On the other side, they need to forecast the countries or regions in which the spike is more likely to occur. The inherent disadvantage of such a strategy is that the trading costs, which are not negligible for emerging markets (Masters (2002)), would be higher due to the increased turnover. The advantage is that the probability of an active strategy to be invested in the next Latin America-1991 combination increases. Overall results in this paper show that the long-term benefits of being diversified in a broad index are statistically insignificant. On the contrary, as our empirical evidence suggested, being in the right region at the right 
time does bring statistically significant benefits commensurate to the higher risk which should compensate the additional costs brought by increased trading.

\section{Figure 2: Correlation Of Several Emerging Market Indexes To The S\&P 500 Composite}

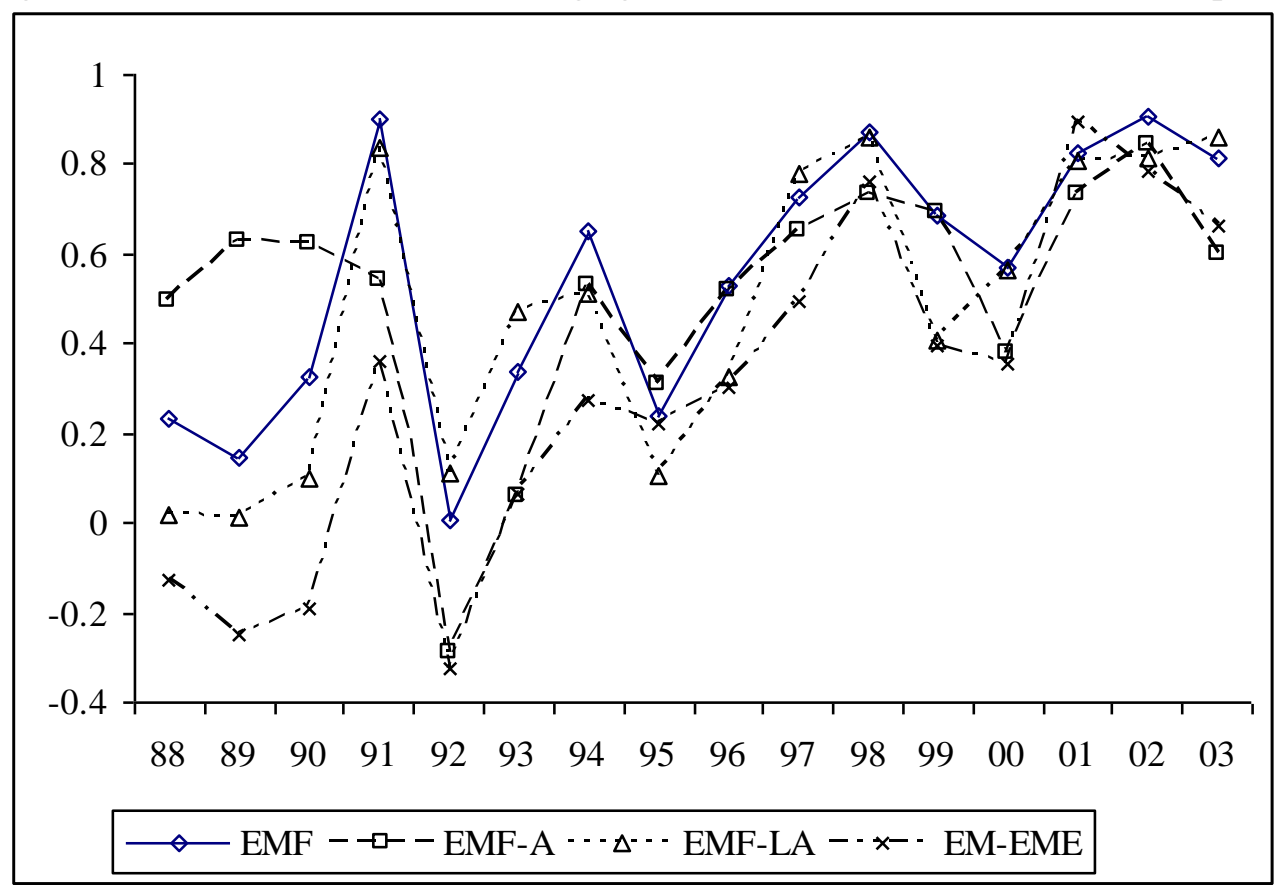

Correlation is measured from January to December for each calendar year.

\section{SUMMARY AND CONCLUSION}

Many researchers have documented the benefit of diversifying into emerging equity markets. The reasoning for this recommendation is that despite the higher risk of these markets, investors can expect higher returns and a low correlation with developed markets, which should increase the performance of a portfolio with a moderate exposure to emerging markets. Our findings show that combining a $10 \%$ proportion of equity of emerging markets with a U.S. index (S\&P 500) produces a small improvement in the average Sharpe ratios. Though the improvement is mainly seen for the broad index EMF and for the Latin America index for the whole sample period, other indices do increase the average SR for other subperiods. However, statistical tests that analyze the stability of such benefit show that the relative improvement is not statistically significant except for one subperiod/region combination.

To analyze the reasons for our marginal results, we test the basic premises of the origins of diversification benefits of investing in EM: higher returns compensating the higher risk and low correlation with the domestic portfolio. Our results show that emerging markets are consistently riskier than the U.S. benchmark. However, contrary to expectations, statistical tests for higher return and low correlations are not consistent; they attain significance only for one subperiod. In general, we find that though volatility of EM has always exceeded that of the S\&P 500, average return has not increased enough to compensate for the higher risk. Furthermore, correlation with S\&P 500 has increased over time. This combination of factors reduces the diversification benefits of investing in broad emerging markets indexes. Nevertheless, evidence in this paper suggests that portfolio managers may benefit from investments in emerging markets that focus on country or regional allocation.

In general, as liberalization of local markets and other globalization efforts continue throughout the world, we can expect a higher participation by investors in emerging equity markets in the future, which may cause the 
correlation with developed markets to strengthen, especially for a broad index, such as EMF. In conclusion, since ex post benefits to U.S. investors diversifying into emerging markets exist only if the relative performance of emerging markets is commensurate to their higher relative risk, investors have to be more selective in the future and be very careful about their expectations.

\section{SUGGESTIONS FOR FUTURE RESEARCH}

A possible extension to this work would be to study the practical role of kurtosis in portfolio allocation. Results shown here and the lack of conclusive empirical evidence suggest a promising area of research, which may become critical to portfolio managers in the future. Other natural additions to the paper would be to perform robustness tests using MSCI country indices and individual ADRs and investigate if the conclusions presented here hold. These lines of research are left for future study.

\section{ENDNOTES}

1 Morgan Stanley Capital International (MSCI) index data is available to the public via the Morgan Stanley web site: www.msci.com

2 As of April 2002 the EMF Index consisted of the following 26 emerging market country indices: Argentina, Brazil, Chile, Colombia, Mexico, Peru, Venezuela, which constitute the EMF Latin America Index; China, India, Indonesia, Korea, Malaysia, Pakistan, Philippines, Taiwan, Thailand, which constitute the EMF Asia Index; Czech Republic, Hungary, Israel, Jordan, Poland, Russia, Turkey, which constitute the EM Europe and Middle East Index; and Egypt, Morocco and South Africa, which are recent additions to EMF and form part of the EM Europe, Middle East and Africa (EM EMEA) Index together with the EM EME constituents.

3 In calculating the Sharpe performance measure, risk-free $\left(R_{f}\right)$ interest rate is assumed to be zero. A monthly risk-free value of zero has negligible impact on the results, and is consistent with how other authors have treated comparative Sharpe calculations among major markets, see Eun and Resnick (1994 and 2001).

4 We stress the results obtained with the geometric mean over those of the arithmetic mean because geometric averages are superior measures of the long-term rate of return.

5 Optimal allocation values are obtained by varying the allocation to EM index until our portfolio performance measure (Sharpe ratio) is maximized for the period in question.

6 If we exclude 1995 from the time series, normality can't be rejected for SR ${ }_{\mathrm{SP} 500}$.

7 Conclusions hold if Sharpe ratios are computed using geometric mean instead of arithmetic mean.

8 Detailed results for different allocation levels are available from the authors upon request.

9 Nevertheless, as explained above, the observation for 1995 exerts a strong influence on results. Excluding it from the analysis brings support to the hypothesis that combining 10\% of EMF-LA with S\&P500 is better than investing in S\&P500.

10 We report that doing t-tests on the monthly returns shows that the average return EMF-LA is significantly higher than the average return of the S\&P 500 at the $10 \%$ significance level.

\section{REFERENCES}

1. Bailey, Warren and Rene M. Stulz. Benefits of International Diversification: The Case of Pacific Basin Stock Markets. Journal of Portfolio Management, Vol. 16, No. 4, pp. 57-61, Summer 1990.

2. Barry, Christopher B., John.W. Peavy, and Mauricio Rodriguez. Performance Characteristics of Emerging Capital Markets. Financial Analyst Journal, Vol. 54, No. 1, pp. 72-80, January/February 1998.

3. Bekaert, Geert, Claude B. Erb, Campbell C. Harvey, and Tadas E. Viskanta Distributional Characteristics of Emerging Market Returns and Asset Allocation. Journal of Portfolio Management, Vol. 24, No. 2, pp. 102116, Winter 1998.

4. Bekaert G. and M. S. Urias Is there a free lunch in emerging market equities? Journal of Portfolio Management, Vol. 25, No. 3, pp. 83-95, Spring 1999

5. De Santis, G. Asset Pricing and Portfolio Diversification: Evidence from Emerging Markets. In S. Claessens and S. Gooptu, eds., Portfolio Investment in Developing Countries. The World Bank Discussion Series, pp. 145-168, 1993. 
6. Divecha, Arjun, Jaime Darch, and Dan Stefek. Emerging Markets: A Quantitative Perspective. Journal of Portfolio Management, Vol. 21, No. 1, pp. 41-50, Fall 1994.

7. Eaker, Mark, Dwight Grant, and Nelson Woodard. Realized rates of return in emerging equity markets. Journal of Portfolio Management, Vol. 26, No. 3, pp. 41-49, Spring 2000.

8. Erb, Claude B., Campbell C. Harvey, and Tadas E. Viskanta. The Making of an Emerging Market. Emerging Markets Quarterly, Vol. 1, No. 1, pp. 14-19, Spring 1997.

9. Errunza, Vihang. Emerging Markets: A new Opportunity for Improving Global Portfolio Performance. Financial Analyst Journal, Vol. 39, No. 5, pp. 51-58, September/October 1983.

10. Errunza, Vihang and Prasad Padmanabhan. Further Evidence on the Benefits of Portfolio Investments in Emerging Markets. Financial Analyst Journal, Vol. 44, No. 4, pp. 76-78, July/August 1988.

11. Eun, Cheol S. and Bruce G. Resnick, International Diversification of Investment Portfolios: U.S. and Japanese Perspectives, Management Science, Vol. 40, No. 1, pp. 140-161, January 1994.

12. Eun, Cheol S. and Bruce G. Resnick. International Financial Management. McGraw-Hill, pp.308-309, 2001.

13. Harvey, Campbell. Predictable risk and returns in Emerging Markets, Review of Financial Studies Vol. 8, No. 3, pp. 773-816, Fall 1995.

14. Harvey, Campbell. Portfolio enhancement using emerging markets and conditioning information. In S. Claessens and S. Gooptu, eds., Portfolio Investment in Developing Countries. The World Bank Discussion Series, pp. 145-168, 1993.

15. Jorion, Philippe and Darius Miller. Investing in Emerging Markets Using Depository Receipts. Emerging Market Quarterly, Vol. 1, No. 1, pp. 7-13, Spring 1997,

16. Levy, Haim and M. Sarnat. International Diversification of Investment Portfolios. American Economic Review, Vol. 60, No. 4, pp. 668-675, September 1970.

17. Masters, Seth J. After the fall. Journal of Portfolio Management, Vol. 26, No. 1, pp.18-26, Fall 1999.

18. Masters, Seth J. Emerging Markets. Journal of Portfolio Management, Vol. 28, No. 3, pp.96-101, Spring 2002. 